\title{
An Estimation of the Thermal Properties of Pu-Rich Metallic Fuel
}

\author{
Naoya Odaira $(\mathbb{D})$ and Yuji Arita $(D)$ \\ University of Fukui, 1-3-33 Kanawa-cho, Tsuruga, Fukui 914-0055, Japan \\ Correspondence should be addressed to Yuji Arita; arita@u-fukui.ac.jp \\ Received 31 March 2019; Revised 25 July 2019; Accepted 2 August 2019; Published 4 September 2019
}

Guest Editor: Pradip Basnet

Copyright (c) 2019 Naoya Odaira and Yuji Arita. This is an open access article distributed under the Creative Commons Attribution License, which permits unrestricted use, distribution, and reproduction in any medium, provided the original work is properly cited.

\begin{abstract}
$\mathrm{Pu}$-rich metallic fuel is promising for transuranic element burners. In this study, we calculated the thermal properties of Pu-rich metallic fuel. The thermal conductivity was calculated by using both Nordheim's rule and Wiedemann-Franz law. The thermal conductivity of $\mathrm{Pu}-40 \mathrm{Zr}\left(14.3 \mathrm{Wm}^{-1} \cdot \mathrm{K}^{-1}\right.$ at $\left.600 \mathrm{~K}\right)$ was much lower than that of $\mathrm{U}-10 \mathrm{Zr}\left(23.5 \mathrm{Wm}^{-1} \cdot \mathrm{K}^{-1}\right.$ at $\left.600 \mathrm{~K}\right)$, another candidate metallic fuel. This addresses the metallic fuel has much lower durability in accidental situations than U-Zr metallic fuel. Thus, we also calculated thermal conductivity of the $\mathrm{Pu}-20 \mathrm{U}-20 \mathrm{Zr}$ alloy. The result shows uranium addition to the $\mathrm{Pu}-\mathrm{Zr}$ alloy increased the thermal conductivity. In addition, we calculated the melting point of the $\mathrm{Pu}-(0-80 \mathrm{U})-20 \mathrm{Zr}$ alloy and the result shows uranium addition increased melting point. This result suggests the accident tolerance of the Pu-rich metallic fuel increases by adding uranium.
\end{abstract}

\section{Introduction}

Fast reactors can burn transuranic elements (TRUs; $\mathrm{Pu}$, $\mathrm{Np}, \mathrm{Am}$, and $\mathrm{Cm}$ ) effectively owing to their higher fissionto-neutron-capture ratio than light-water reactors (LWRs). LWRs will be the dominant nuclear power plants for at least the next few decades. To burn the TRUs produced from LWRs, it is necessary to improve the TRU burning capability of fast reactors. Because uranium TRUfueled fast reactors also produce TRUs, the most effective approach is to use uranium-free TRU fuel because this does not produce additional TRUs. Such a system could reduce the capacity of the TRU burner units and the associated fuel cycle facilities to about $1 / 5$ and $1 / 8$, respectively. There have been many studies on uranium-free or fertile-free fuel systems [1-3]; however, difficulties remain, such as the requirement for new reprocessing technology. For example, reprocessing technology for producing TRU-burning oxide fuel is required to separate actinides and lanthanides, which have similar chemical behavior [4]. In addition, the remote control technology for reprocessing needs modifications because of high radioactivity of minor actinides. By contrast, uraniumfree TRU metal could be reprocessed and fabricated based on pyroprocess and injection-casting technologies without substantial modification [5].

In the United States, many studies concerning uraniumfree metal fuels have been carried out. Most notably, the US accelerator-driven transmutation of waste (ATW) program investigated an accelerator-driven transmutation system coupled with a subcritical fast reactor using uranium-free metal fuel [6-9]. In such systems, thermal properties, such as the heat capacity, thermal conductivity, and melting temperatures of the fuel, are important for the design of the core structure of the burning reactor.

In our previous study, we estimated the melting temperature of TRU-Zr alloys [10] and the thermal properties of $\mathrm{Pu}$-rich alloys [11]. In the present study, we evaluate the thermal properties of $\mathrm{Pu}-40 \mathrm{Zr}(\mathrm{Pu}-64 \mathrm{at} \% \mathrm{Zr})$, a candidate material for TRU burners, and Pu-20U-20Zr (Pu-15at\%U$40 \mathrm{at} \% \mathrm{Zr}$ ) in a more relevant way.

\section{Estimation of Thermal Properties}

We calculated the heat capacity, thermal conductivity, and solidus and liquidus temperatures of the $\mathrm{Pu}-40 \mathrm{Zr}$ and the $\mathrm{Pu}-\mathrm{U}-\mathrm{Zr}$ alloys because experimental work with plutonium is difficult to obtain approval in Japan. The heat capacity of 
alloys was estimated using the Neumann-Kopp law, which is equivalent to an additive law. Although the heat capacity varied considerably with phase changes, the estimated values for $\mathrm{Pu}-40 \mathrm{Zr}$ and $\mathrm{Pu}-20 \mathrm{U}-20 \mathrm{Zr}$ alloys were similar if their phases were the same.

Generally, the thermal conductivity at high temperatures is calculated from the heat capacity, thermal diffusivity, and density. The heat capacity and density are often estimated from the Neumann-Kopp law and Vegard's law. However, the thermal diffusivity is comparatively difficult to estimate because it varies significantly with composition, phase, and temperature. Another common way to estimate the thermal conductivity of metallic materials is to use the Wiedemann-Franz law, which multiplies the electrical conductivity, absolute temperature, and Lorentz number [12]. Unfortunately, however, the electrical conductivity of $\mathrm{Pu}-\mathrm{Zr}$ alloys had not been reported. Nordheim's rule is a common way to estimate the electrical conductivity of element although its use is limited to alloys that form a solid solution. Fortunately, $\mathrm{Pu}-\mathrm{Zr}$ and $\mathrm{Pu}-\mathrm{U}-\mathrm{Zr}$ alloys are considered to form a body-centered cubic (bcc) solid solution from related binary systems and the U-Pu-Zr ternary system $[13,14]$. Therefore, the thermal conductivity of $\mathrm{Pu}-40 \mathrm{Zr}$ and $\mathrm{Pu}-20 \mathrm{U}-20 \mathrm{Zr}$ alloys was estimated using both the Wiedemann-Franz law and Nordheim's rule with the Nordheim coefficients.

Finally, we calculated the solidus and liquidus temperatures using Thermo-Calc, which is based on the CALPHAD method. The phase diagrams of the U-Zr, Pu-Zr, and U-Pu systems are available in the literature; thus, we calculated the liquidus and solidus temperatures by creating a pseudobinary system of the $\mathrm{Pu}-(0-80 \mathrm{U})-20 \mathrm{Zr}$ alloy.

2.1. Heat Capacity. Figure 1 shows the data available in the literature for the $\mathrm{U}-\mathrm{Zr}$ alloy [15] and the constituents: uranium, zirconium, and plutonium [16, 17]. There are anomalous peaks for the heat capacities of all three elements, which are caused by their phase transitions. The heat capacity of a compound can be estimated using the Neumann-Kopp (additive) law [18, 19]. Specifically, if a solid compound, $M$, is formed from elements $A, B$, and $C$ by a chemical reaction:

$$
a A+b B+c C \longrightarrow M
$$

then the heat capacity of the compound $C_{\mathrm{PM}}$ is expressed by the heat capacity of each element as follows:

$$
C_{\mathrm{PM}}=a C_{\mathrm{PA}}+b C_{\mathrm{PB}}+c C_{\mathrm{PC}} \text {. }
$$

The heat capacity of the U-Zr alloy measured by Matsui et al. [20] was similar to that calculated using the Neumann-Kopp law. Therefore, it may be possible to use it to determine the heat capacities of $\mathrm{Pu}-\mathrm{Zr}$ and $\mathrm{Pu}-\mathrm{U}-\mathrm{Zr}$ alloys. Plutonium has many phase transitions, at which its heat capacity changes. For the Pu-Zr system created by Kurata [21], the $\mathrm{Pu}-40 \mathrm{Zr}$ alloy had two phases from room temperature to melting point, and the phase-transition temperature was approximately $902 \mathrm{~K}$ (Figure 2).

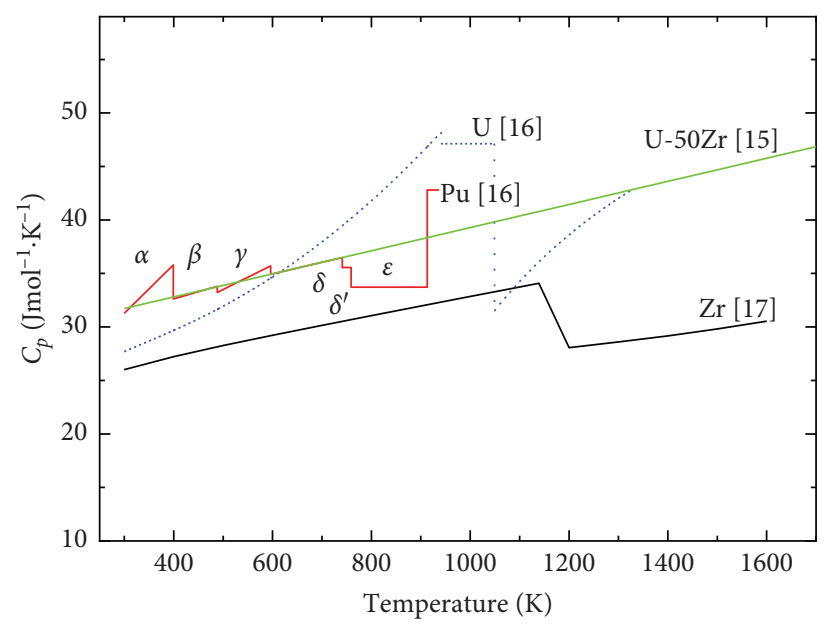

FIgURE 1: Literature data of the heat capacity of $\mathrm{U}-\mathrm{Zr}$ and $\mathrm{U}, \mathrm{Zr}$, and $\mathrm{Pu}$ elements [15-17].

The low-temperature phase is a face-centered cubic (fcc) structure, and the high-temperature phase is a bcc structure. Below $902 \mathrm{~K}$, the heat capacity of plutonium in our calculation was determined by interpolation and/or extrapolation of the value for the $\beta$ and $\delta$ (fcc) phases. Above $902 \mathrm{~K}$, the heat capacity was determined by extrapolation of the $\varepsilon$ (bcc) phase. The heat capacity of zirconium was determined in a similar manner. Figure 3 shows the estimated heat capacity for $\mathrm{Pu}-40 \mathrm{Zr}$ and $\mathrm{Pu}-20 \mathrm{U}-20 \mathrm{Zr}$ alloys. For the Pu-20U-20Zr alloy, the phase-transition temperature was approximately $900 \mathrm{~K}$, based on the available phase diagrams. The obtained fitting equations were as follows:

$$
\begin{aligned}
\mathrm{Pu}-\mathrm{Zr} C P\left(\mathrm{Jmol}^{-1} \cdot \mathrm{K}^{-1}\right)= & 25.942+0.011614 \times T(\mathrm{~K}) \\
- & 1.5751 \times 10^{-6} \times T(\mathrm{~K})^{2} \\
& : 298<T<902 \mathrm{~K} \\
= & 25.587+0.00246 \times T(\mathrm{~K}) \\
& : 902<T<1330 \mathrm{~K}, \\
\mathrm{Pu}-\mathrm{U}-\mathrm{Zr} C P\left(\mathrm{Jmol}^{-1} \cdot \mathrm{K}^{-1}\right)= & 26.627+0.00995 \times T(\mathrm{~K}) \\
& +2.92401 \times 10^{-6} \times T(\mathrm{~K})^{2} \\
& : 298<T<900 \mathrm{~K} \\
= & 32.9715-0.00299 \times T(\mathrm{~K}) \\
+ & 1.94196 \times 10^{-6} T(\mathrm{~K})^{2} \\
: & 900<T<1330 \mathrm{~K} .
\end{aligned}
$$

Although the phase transition temperature was different from the U-50Zr alloy, the value of $C p$ was not so different from it which has a similar ratio of zirconium with the $\mathrm{Pu}$ 40Zr alloy.

2.2. Thermal Conductivity. Wiedemann-Franz law is known as a specific rule in metallic elements, which connect thermal conductivity with electrical conductivity [12]: 


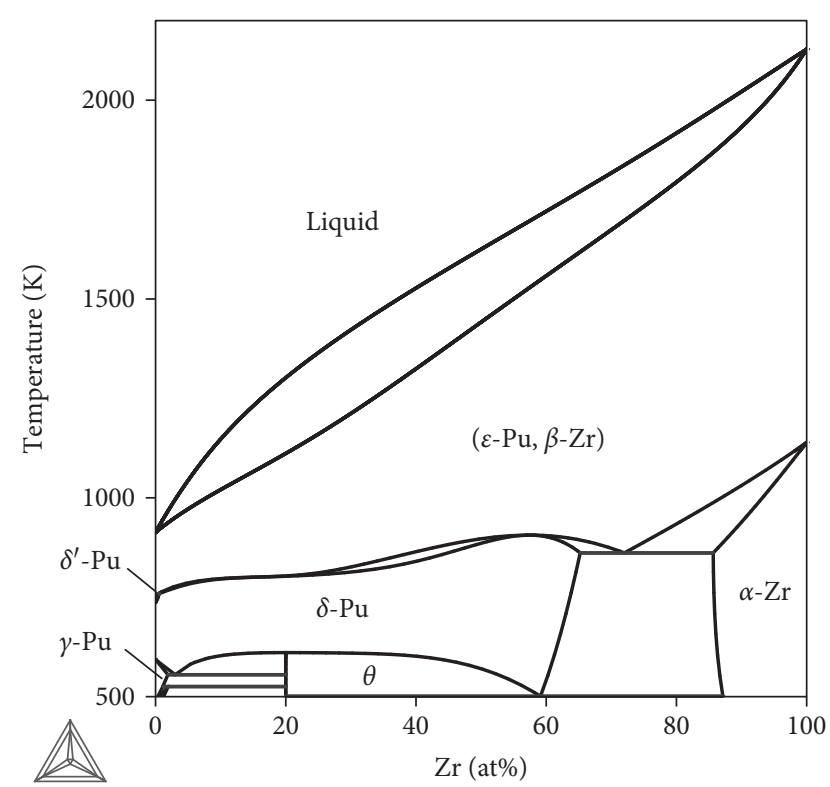

Figure 2: Phase diagram of the Pu-Zr system [21, 22].

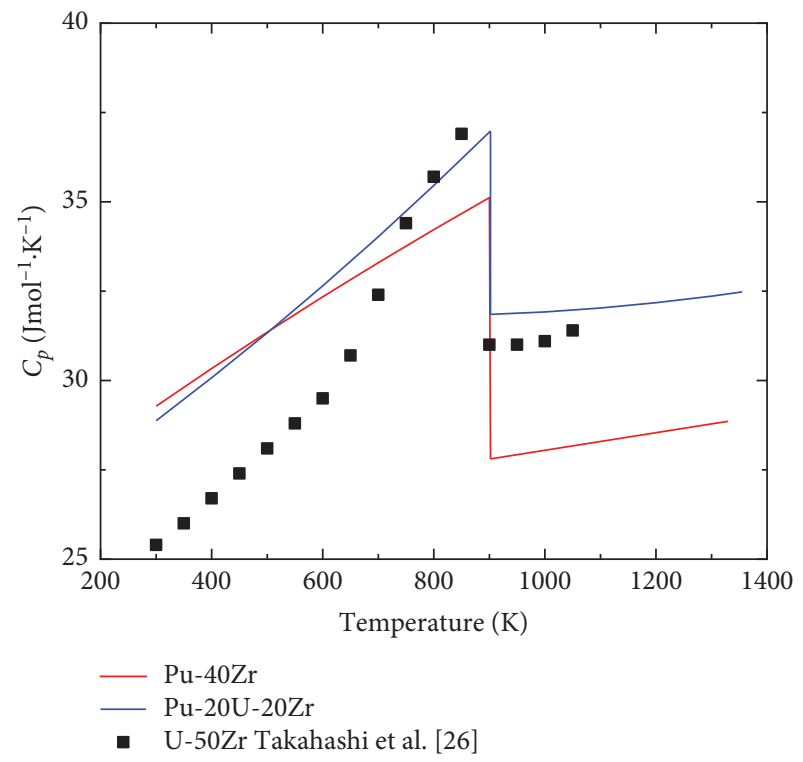

FIgURE 3: Estimated heat capacity of Pu-40Zr and Pu-20U-20Zr alloys.

$$
\kappa=L \sigma T=\frac{\mathrm{LT}}{\rho},
$$

where $\kappa$ is the thermal conductivity $\left(\mathrm{Wm}^{-1} \cdot \mathrm{K}^{-1}\right), \sigma$ is the electrical conductivity $\left(\Omega^{-1} \cdot \mathrm{m}^{-1}\right), \rho$ is the electrical resistivity $(\Omega \mathrm{m}), L$ is the Lorentz number, and $T$ is the temperature $(\mathrm{K})$. The Lorentz number is typically derived from the experimental measurement of thermal and electrical conductivity. However, it can also be derived from quantum mechanics, giving a value of $L=2.44 \times 10^{-8}\left(\mathrm{~W} \Omega \mathrm{K}^{-2}\right)$, which is close to that of uranium, plutonium, and zirconium. Thus, we used this theoretical value of the Lorentz number in this study. For alloys form solid solution, Nordheim found that the electrical resistivity has a $x(1-x)$ dependence, as follows [23]:

$$
\rho_{m}=\rho_{A}(1-x)+\rho_{B} x+c x(1-x),
$$

where $\rho_{m}, \rho_{A}$, and $\rho_{B}$ are the electrical resistivity of the mixture and elements $A$ and $B, x$ is the atomic fraction of element $B$, and $c$ is the Nordheim coefficient, which is an element-dependent parameter. For example, for the $\mathrm{Cu}-\mathrm{Au}$ alloy, the Nordheim coefficient of $\mathrm{Cu}$-rich-Au alloys and $\mathrm{Au}$ rich-Cu alloys are different [24]. Thus, we treated the Nordheim coefficients of the U-rich-Zr alloy and Zr-rich-U alloy separately in this paper.

From the Wiedemann-Franz law and Nordheim's rule, the thermal conductivity is considered to have the same dependence as the electrical conductivity [25]:

$$
\kappa_{1}=\frac{1}{(1-x) / \kappa_{A}+x / \kappa_{B}+c_{1} x(1-x) /(\mathrm{LT})},
$$

where $\kappa_{1}, \kappa_{A}$, and $\kappa_{B}$ are the thermal conductivity $\left(\mathrm{Wm}^{-1} \cdot \mathrm{K}^{-1}\right)$ of the mixture and elements $\mathrm{A}$ and $\mathrm{B}$, respectively, $x$ is the atomic fraction of element $\mathrm{B}, c_{1}$ is the Nordheim coefficient, $L$ is the Lorentz number, and $T$ is the temperature. Because equation (5) only applies for binary alloys, we extended it to treat ternary alloys as a mixture of a binary alloy and third element as follows:

$$
\kappa_{2}=\frac{1}{(1-x) / \kappa_{1}+x / \kappa_{C}+c_{2} x(1-x) /(L T)},
$$

where $\kappa_{2}, \kappa_{1}$, and $\kappa_{C}$ are the thermal conductivity $\left(\mathrm{Wm}^{-1} \cdot \mathrm{K}^{-1}\right)$ of the ternary alloy, binary alloy, and third element $C$, respectively, and $x$ is the atomic fraction of element $C$. In our estimation, elements $A, B$, and $C$ were $\mathrm{U}, \mathrm{Zr}$, and $\mathrm{Pu}$, respectively, to obtain the Nordheim coefficients. To obtain the thermal conductivity of $\mathrm{Pu}-\mathrm{Zr}$ and $\mathrm{Pu}-\mathrm{U}-\mathrm{Zr}$, elements $A, B$, and $C$ were $\mathrm{Pu}, \mathrm{Zr}$, and $\mathrm{U}$, respectively.

The thermal conductivity of $\mathrm{U}-\mathrm{Zr}$ and $\mathrm{U}-\mathrm{Pu}-\mathrm{Zr}$ alloys were taken from the work of Takahashi et al. [26] and reports from the Argonne National Laboratory (ANL) [27, 28]. These values were fitted into the above equations to obtain the Nordheim coefficients $c_{1}$ and $c_{2}$ for $\mathrm{U}-\mathrm{Zr}$ and $\mathrm{U}-\mathrm{Pu}-\mathrm{Zr}$ alloys as temperature-dependent linear functions. To derive these functions, we fitted the temperature dependences of the thermal conductivity of uranium, zirconium, and plutonium using the following equation from available data $[29,30]$ :

$$
\kappa=a+b T+c T^{2}+d T^{3} .
$$

Obtained fitting parameters are shown in Table 1. We obtained the thermal conductivity of $\mathrm{Pu}-\mathrm{Zr}$ and $\mathrm{Pu}-\mathrm{U}-\mathrm{Zr}$ based on the assumption that their Nordheim coefficients were the same as those of $\mathrm{U}-\mathrm{Zr}$ and $\mathrm{U}-\mathrm{Pu}-\mathrm{Zr}$ alloys. The Nordheim coefficients for $\mathrm{U}-\mathrm{Zr}$ and $\mathrm{U}-\mathrm{Pu}-\mathrm{Zr}$ alloys are summarized in Table 2. In Figures 4 and 5, we compare the thermal conductivities obtained in the present study using the obtained Nordheim coefficients with those of the available data [26-28]. These show relatively close to measured thermal conductivity for both $\mathrm{U}-\mathrm{Zr}$ and $\mathrm{U}-\mathrm{Pu}-$ 
TABLE 1: Fitted parameters for each element $[29,30]$.

\begin{tabular}{lcccc}
\hline & & $\kappa=a+b T+c T^{2}+d T^{3}$ & & $c$ \\
& $a$ & $b$ & -21.69 & $d$ \\
$\mathrm{U}$ & $3.739 \times 10^{-6}$ & 0.01837 & 27.48 & - \\
$\mathrm{Zr}$ & $2.090 \times 10^{-5}$ & -0.02515 & $9.278 \times 10^{-3}$ & - \\
$\mathrm{Pu}$ & $-5.288 \times 10^{-8}$ & $6.439 \times 10^{-5}$ & -1.534 \\
\hline
\end{tabular}

TABLE 2: Obtained Nordheim coefficients for U-Zr and U-Pu-Zr alloys.

\begin{tabular}{lccc}
\hline & $c=a+b T$ (Nordheim coefficient) & & $a$ \\
For published data & For estimation & $7.985 \times 10^{-6}$ & $-7.436 \times 10^{-9}$ \\
\hline Zr-rich (U-Zr alloy) & $\mathrm{Pu}-40 \mathrm{Zr}(\mathrm{Pu}-64 \mathrm{at} \% \mathrm{Zr})$ & $1.581 \times 10^{-6}$ & $-1.619 \times 10^{-9}$ \\
U-rich (U-Zr alloy) & - & $2.747 \times 10^{-6}$ & $-1.847 \times 10^{-9}$ \\
U-Zr-rich (U-Pu-Zr alloy) & $\mathrm{Pu}-20 \mathrm{U}-20 \mathrm{Zr}(\mathrm{Pu}-15 \mathrm{at} \% \mathrm{U}-40 \mathrm{at} \% \mathrm{Zr})$ & & \\
\hline
\end{tabular}

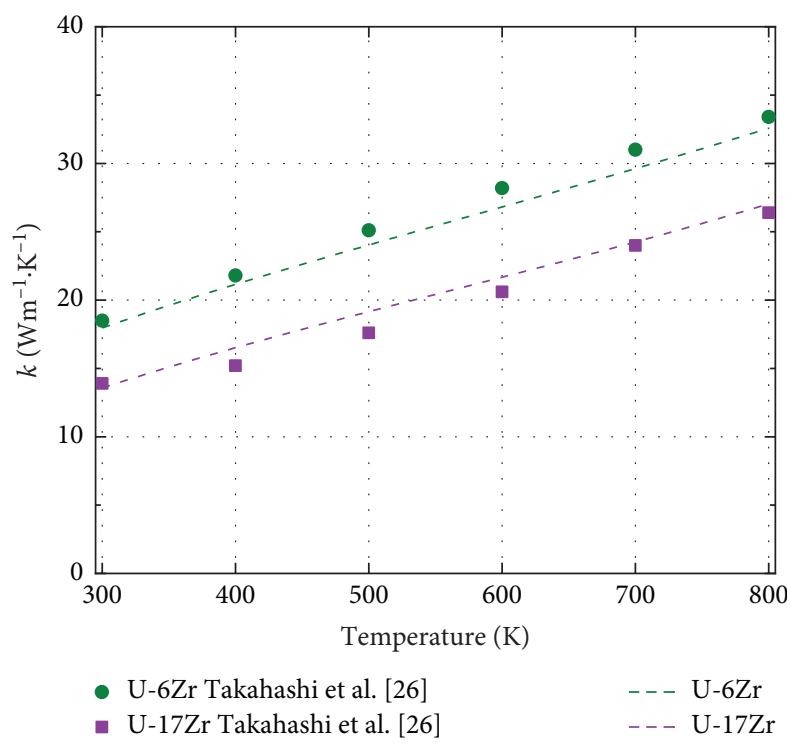

(a)

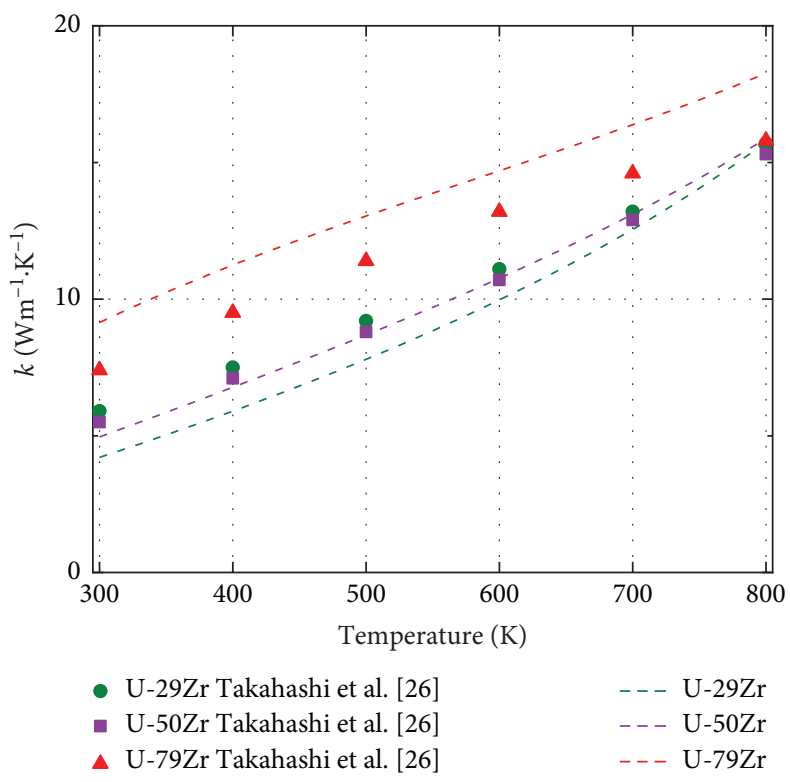

(b)

FIGURE 4: Comparison between the obtained thermal conductivity-temperature correlations (broken line) (present work) for (a) U-rich and (b) Zr-rich U-Zr alloys and the results of Takahashi et al. [26] (each point).

$\mathrm{Zr}$ alloys. For the U-79Zr alloy, our correlation showed higher thermal conductivity than experimental data. However, if zirconium content is below $50 \mathrm{wt} \%$, our correlation showed sufficiently agreed well. Obtained Nordheim coefficients were based on these experimental data. These experimental data were only available below $1173 \mathrm{~K}$, and this is the temperature limitation in the present experiment. The $\mathrm{Pu}-40 \mathrm{Zr}$ alloy had a significantly lower thermal conductivity than plutonium because of the effect of zirconium addition. However, the thermal conductivity of the Pu-20U-20Zr alloy was improved and it was close to that of plutonium because of the presence of uranium (Figure 6).

2.3. Solidus and Liquidus Temperatures. Solidus and liquidus temperatures of the $\mathrm{Pu}-\mathrm{U}-\mathrm{Zr}$ alloy $(\mathrm{Pu}-(0-80 \mathrm{U})-20 \mathrm{Zr})$ were calculated by Thermo-Calc [22] by creating a pseudo-binary phase diagram. Thermo-Calc is the calculation code based on the CALPHAD method, which creates phase diagrams and phase equilibria. A description of the CALPHAD method is provided elsewhere [31]. We used the database for the calculation to create $\mathrm{U}-\mathrm{Zr}, \mathrm{Pu}-\mathrm{Zr}, \mathrm{U}-\mathrm{Pu}$, and $\mathrm{U}-\mathrm{Pu}-\mathrm{Zr}$ systems based on the most recent data of the Gibbs free energy reported by Kurata $[13,14]$ although the Pu-rich region is not well understood in the $\mathrm{U}-\mathrm{Pu}-\mathrm{Zr}$ system. Verification of the database provided by Kurata is performed by D. E. Janney et al. [32]. There is no experimental data of the melting points for the $\mathrm{Pu}-\mathrm{U}-\mathrm{Zr}$ alloys, and thus, experimental measurement will be mandatory. To judge whether $\mathrm{Pu}$-rich metallic fuel can be used in fast reactors, the system should be evaluated. Our results are shown in Figure 7, and fitting was performed with uranium content as follows: 


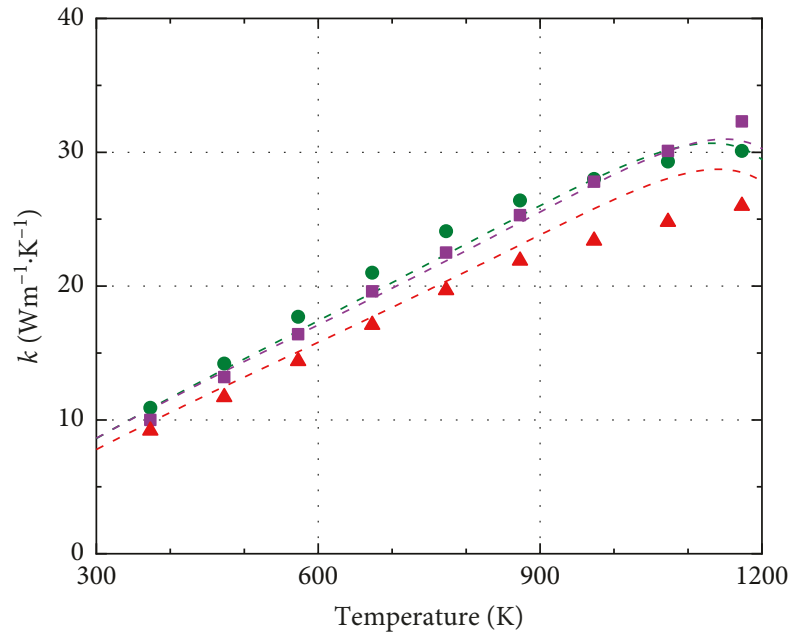

- U-16.2Pu-6.2Zr ANL-7230

- U-14.7Pu-9.7Zr ANL-7230

- U-18.4Pu-11.5Zr ANL-7230

(a)

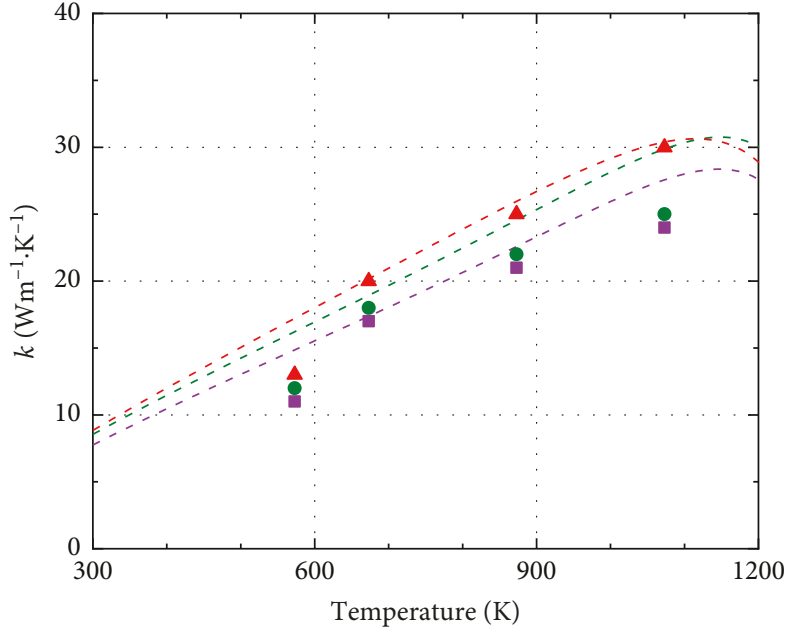

- U-15Pu-10Zr ANL-7155

- U-18.4Pu-14.1Zr ANL-7155

- U-17.1Pu-3.4Zr ANL-7155

(b)

Figure 5: Comparison between the obtained thermal conductivity-temperature correlations (broken line) (present work) for the U-Pu-Zr alloy and data from (a) ANL-7230 (U-16.2Pu-6.2Zr, U-14.7Pu-9.7Zr, and U-18.4Pu-11.5Zr alloys (in wt\%) and (b) ANL-7155 (U-15Pu$10 \mathrm{Zr}, \mathrm{U}-18.4 \mathrm{Pu}-14.1 \mathrm{Zr}$, and $\mathrm{U}-17.1 \mathrm{Pu}-3.4 \mathrm{Zr}$ [wt\%] alloys (in wt\%) [27, 28] (each point).

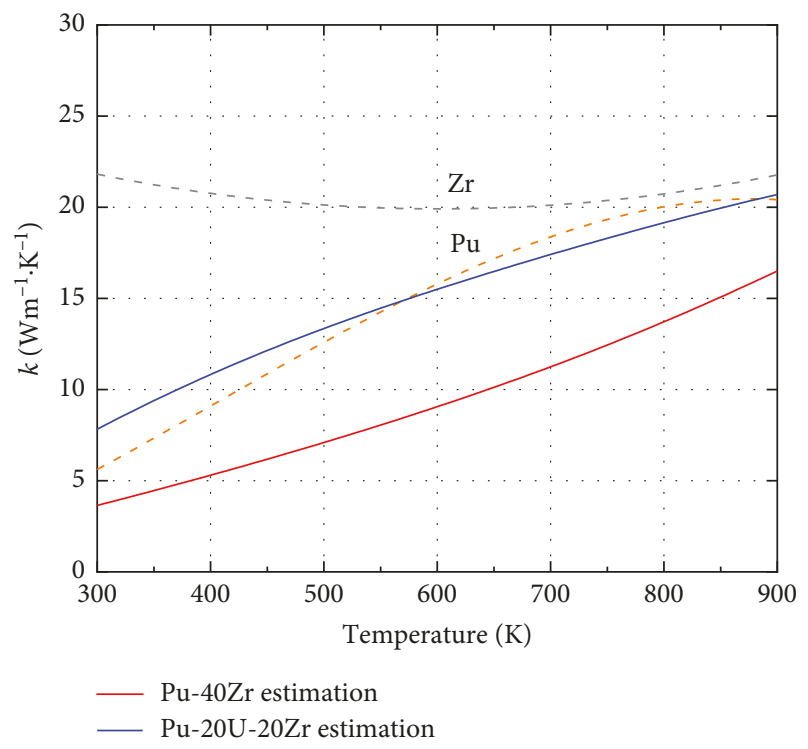

Figure 6: Estimated thermal conductivity of $\mathrm{Pu}-\mathrm{Zr}$ and $\mathrm{Pu}-\mathrm{U}-\mathrm{Zr}$ alloys $[29,30]$.

$$
\begin{aligned}
& T_{\text {liq }}(K)=1530.5+385.07 \times W_{\mathrm{U}}-77.635 \times W_{\mathrm{U}}^{2}, \\
& T_{\text {sol }}(K)=1321.1+38.449 \times W_{\mathrm{U}}+648.5 \times W_{\mathrm{U}}^{2},
\end{aligned}
$$

where $T_{\text {liq }}$ and $T_{\text {sol }}$ are the liquidus and solidus temperatures, respectively, and $W_{U}$ is the weight fraction of uranium. Accordingly, both $T_{\text {liq }}$ and $T_{\text {sol }}$ increase with increasing uranium content. We calculated $T_{\text {liq }}$ and $T_{\text {sol }}$ values of 1321.1 and $1530.5 \mathrm{~K}$ for the $\mathrm{Pu}-20 \mathrm{Zr}$ alloy which were agreed well with the $\mathrm{Pu}-\mathrm{Zr}$ system [13]. We also calculated them of 1705.4 and $1788.9 \mathrm{~K}$ for the U-20Zr alloy. These values were

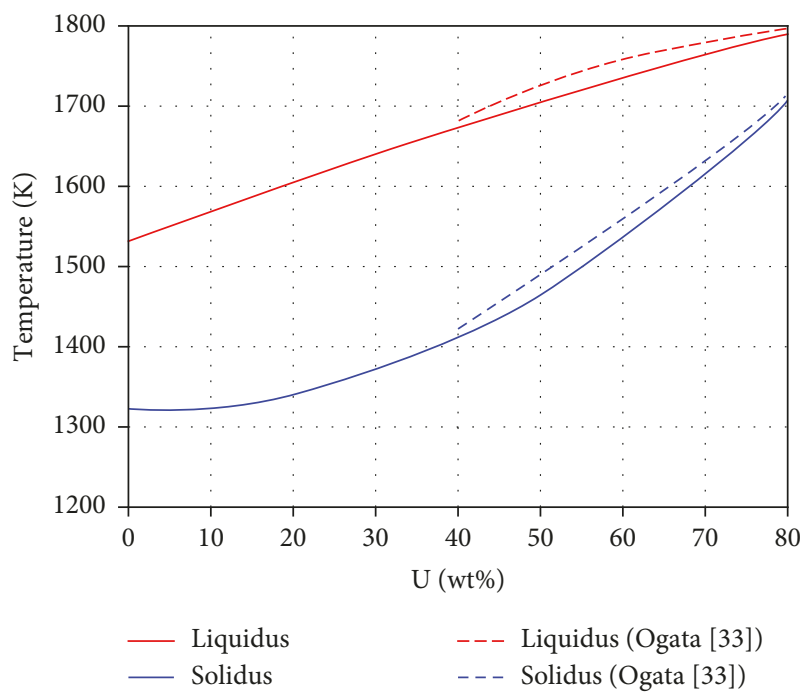

Figure 7: Estimated solidus and liquidus temperatures for the $\mathrm{Pu}-$ $\mathrm{U}-20 \mathrm{Zr}$ alloy $[33,34]$.

slightly lower than those for the U-20Zr alloy calculated by the correlation produced by Ogata, as shown in Figure 7 $[33,34]$.

\section{Conclusion}

U-free metallic alloy fuel has important advantages for use in TRU burners. Most importantly, we showed theoretically that the thermal conductivity of the $\mathrm{Pu}-40 \mathrm{Zr}$ alloy was lower than that of the U-Zr alloys, which limits the core power. This addresses the metallic fuel has much lower durability in 
accidental situation than the U-Zr metallic fuel. To gain the safety margin, we also provided the estimation for the $\mathrm{Pu}$ rich metallic fuel with small amount of uranium addition. However, the addition of uranium to the $\mathrm{Pu}-\mathrm{Zr}$ alloy increased its thermal conductivity and solidus temperature. Despite these advantages, it should be noted that uranium addition could lead to lower efficiency in TRU burners.

\section{Data Availability}

No data were used to support this study.

\section{Disclosure}

Our previous work was presented in NuMat2018 at Seattle, entitled "An estimation of the thermal properties of Pu-rich metallic fuel," P1.008. This research was conducted as the Nuclear System Research and Development program under a contract with the Ministry of Education, Culture, Sports, Science and Technology (MEXT) in Japan during the fiscal year of 2014 to 2017. The title was "Innovative metallic fuel design and development of the production technology for TRU burning."

\section{Conflicts of Interest}

The authors declare that there are no conflicts of interest regarding the publication of this study.

\section{Acknowledgments}

We thank Adam Brotchie, PhD, from Edanz Group (http:// www.edanzediting.com/ac)for editing a draft of this manuscript.

\section{References}

[1] T. Yamashita, H. Kuramoto, H. Akie et al., "Rock-like oxide fuels and their burning in LWRs," Journal of Nuclear Science and Technology, vol. 39, no. 8, pp. 865-871, 2002.

[2] M. Osaka, S. Hiroyuki, M. Kato et al., "Research and development of minor actinide-containing fuel and target in a future integrated closed cycle system," Journal of Nuclear Science and Technology, vol. 44, no. 3, pp. 309-316, 2007.

[3] N. Messaoudi and J. Tommasi, "Fast burner reactor devoted to minor actinide incineration," Nuclear Technology, vol. 137, no. 2, pp. 84-96, 2002.

[4] OECD/NEA, State-of-the-Art Report on the Progress of Nuclear Fuel Cycle Chemistry, NEA. No.7267, Paris, France, 2018.

[5] K. Arie, Y. Tsuboi, A. Hara, Y. Arita, and H. Ohta, "Fast reactors and related fuel cycles: next generation nuclear systems for systainable development FR17," in Proceedings of the IAEA (International Atomic Energy Agency), Yekaterinburg, Russian Federation, June 2017.

[6] R. N. Hill and H. S. Khalil, Emerging Nuclear Energy and Transmutation Systems: Core Physics and Engineering Aspects, Argonne National Laboratory, Lemont, IL, USA, 2000.

[7] D. E. Beller, G. J. Van Tuyle, D. Bennett et al., "The U.S. accelerator transmutation of waste program," Nuclear Instruments and Methods in Physics Research Section A: Accelerators, Spectrometers, Detectors and Associated Equipment, vol. 463, no. 3, pp. 468-486, 2001.
[8] F. Heidet, T. K. kim, and T. A. Taiwo, "Thorium-fueled breed and burn core with low enriched uranium support," in 2013 ANS Winter Meeting, Washington, DC, USA, November 2013.

[9] M. K. Meyer, "Fuel design for the U.S. accelerator driven transmutation system," in Paper Presented at the Nuclear Application in the New Millennium, Reno, NV, USA, November 2001.

[10] Y. Arita, Y. Tsuboi, and H. Ohta, Innovative TRU Burning Fast Reactor Cycle Using Uranium-Free TRU Metal Fuel (2) Fundamental Properties of Uranium-free TRU-Zr Metal Fuel, GLOBAL2015, Paris, France, 2015.

[11] N. Odaira and Y. Arita, "An estimation of the thermal properties of $\mathrm{Pu}$-rich metallic fuel," in Proceedings of NuMat2018, Seattle, WA, USA, October 2018.

[12] R. Franz and G. Wiedemann, "Ueber die wärme-leitungsfähigkeit der metalle," Annalen der Physik und Chemie, vol. 165 , no. 8 , pp. 497-531, 1853.

[13] M. Kurata, "Phase Diagrams of Actinide Alloys, no. 2.05," in Comprehensive Nuclear Materials, Elsevier, Amsterdam, Netherlands, 2012.

[14] M. Kurata, "Thermodynamic assessment of the $\mathrm{Pu}-\mathrm{U}, \mathrm{Pu}-\mathrm{Zr}$, and Pu-U-Zr systems," Calphad, vol. 23, no. 3-4, pp. 305-337, 1999.

[15] Y. Takahashi, K. Yamamoto, T. Ohsato, H. Shimada, T. Terai, and M. Yamawaki, "Heat capacities of uranium-zirconium alloys from 300 to $1100 \mathrm{~K}$," Journal of Nuclear Materials, vol. 167, pp. 147-151, 1989.

[16] R. J. M. Konings and O. Beneš, "The thermodynamic properties of the f-elements and their compounds. I. The lanthanide and actinide metals," Journal of Physical and Chemical Reference Data, vol. 39, no. 4, Article ID 043102, 2010.

[17] E. H. P. Cordfunke and R. J. M. Konings, Themochemical Data for Reactor Materials and Fission Products, North-Holland, Amsterdam, Netherlands, 1990.

[18] J. Leitner, P. Voňka, D. Sedmidubský, and P. Svoboda, "Application of Neumann-Kopp rule for the estimation of heat capacity of mixed oxides," Thermochimica Acta, vol. 497, no. 1-2, pp. 7-13, 2010.

[19] H. Kopp, "Investigations of the specific heat of solid bodies," Philosophical Transactions of the Royal Society of London, vol. 155, pp. 71-202, 1865.

[20] T. Matsui, T. Natsume, and K. Naito, "Heat capacity measurements of $\mathrm{U} 0.80 \mathrm{Zr} 0.20$ and $\mathrm{U} 0.80 \mathrm{Mo} 0.20$ alloys from room temperature to $1300 \mathrm{~K}$," Journal of Nuclear Materials, vol. 167, pp. 152-159, 1989.

[21] M. Kurata, Innovative nuclear research and development program, Technical Report, Japan Science and Technology Agency (JST), Kawaguchi, Japan, 2007.

[22] https://www.thermocalc.com/.

[23] L. Nordheim, "Zur elektronentheorie der Metalle. II," Annalen der Physik, vol. 401, no. 6, pp. 641-678, 1931.

[24] S. Kasap and P. Capper, Springer Handbook of Electronic and Photonic Materials, Springer International Publiching, Basel, Switzerland, 2017.

[25] Y. Terada, K. Ohkubo, T. Mohri, and T. Suzuki, "Thermal conductivity in nickel solid solutions," Journal of Applied Physics, vol. 81, no. 5, pp. 2263-2268, 1997.

[26] Y. Takahashi, M. Yamawaki, and K. Yamamoto, "Thermophysical properties of uranium-zirconium alloys," Journal of Nuclear Materials, vol. 154, p. 4, 1988.

[27] A. V. Crewe and S. Lawroski, Reactor Development Program Progress Report, Argonne National Laboratory, ANL-7230, Lemont, IL, USA, 1966. 
[28] Argonne National Laboratory, Annual Progress Report for 1965, Argonne National Laboratory, ANL-7155, Lemont, IL, USA, 1965.

[29] Y. S. Touloukian, TPRC Data Series Vol. 1 Thermal Conductivity, IFI/Plenum Press, New York, NY, USA, 1970.

[30] C. A. Alexander and V. E. Wood, "Thermal conductivity of plutonium above room temperature," Journal of Applied Physics, vol. 103, no. 6, 2008.

[31] K. Hack, The SGTE Case Book-Thermodynamics at Work-, ISBN 978-1-84569-215-5, CRC Press LLC, Boca Raton, FL, USA, 2008.

[32] D. E. Janney, C. A. Papesch, and S. C. Middlemas, FCRD Advanced Reactor (Transmutation) Fuels Handbook, INL/ EXT-15-36520, Idaho National Laboratory, Idaho Falls, ID, USA, 2016.

[33] T. Ogata, "Irradiation behavior and thermodynamic properties of metallic fuel," Journal of Nuclear Science and Technology, vol. 39, no. 3, pp. 675-681, 2002.

[34] T. Ogata, "Metal Fuel, no. 3.01," in Comprehensive Nuclear Materials, Elsevier, Amsterdam, Netherlands, 2012. 


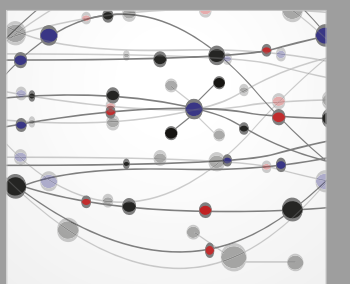

The Scientific World Journal
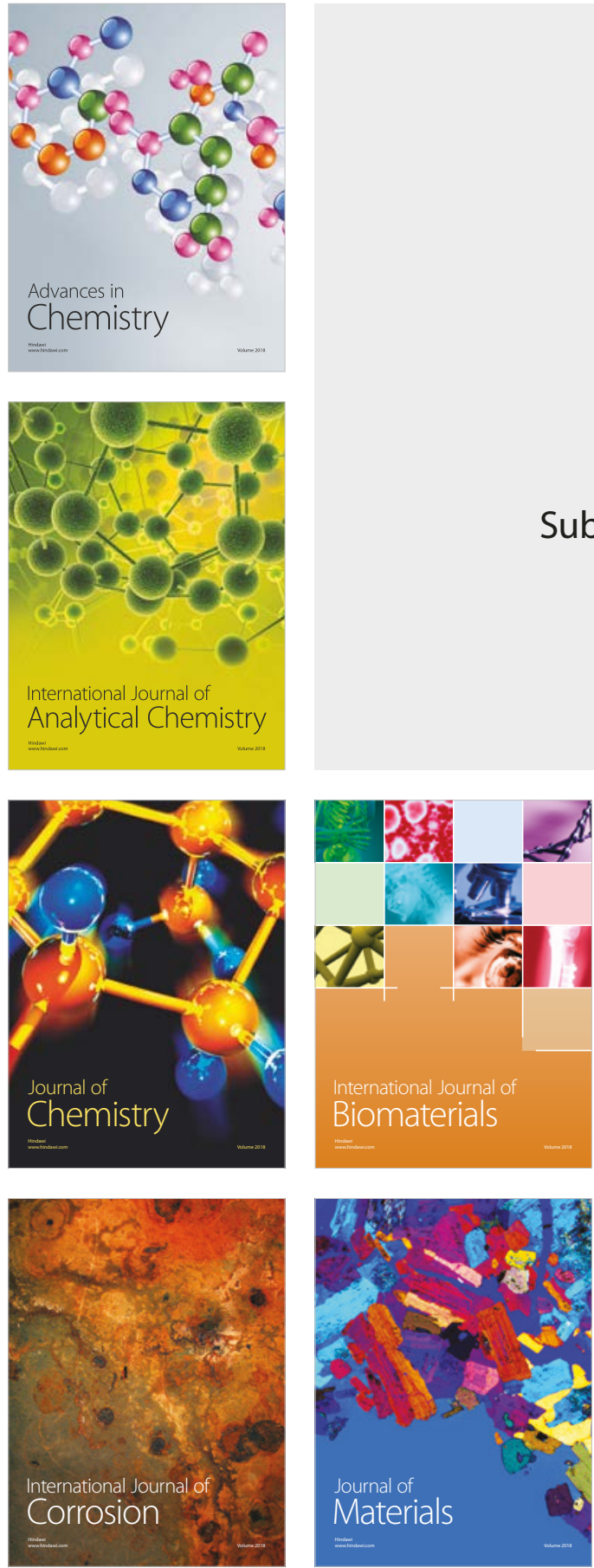

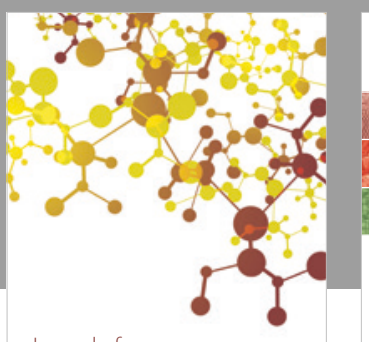

Journal of

Applied Chemistry
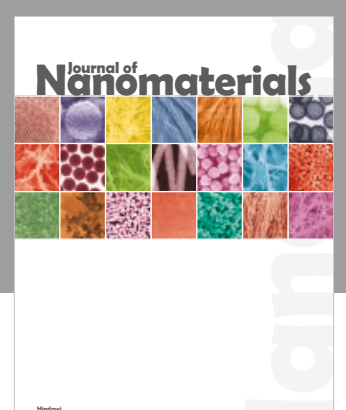

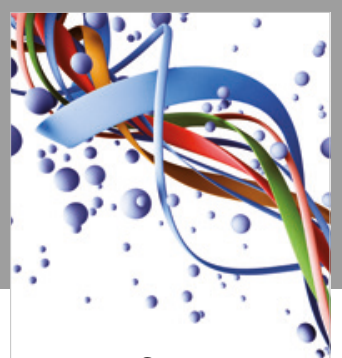

Scientifica

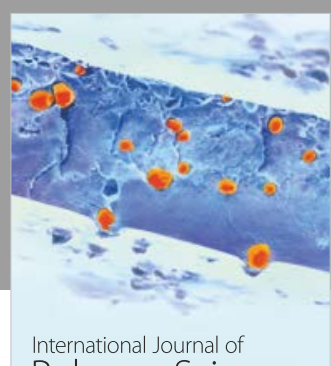

Polymer Science

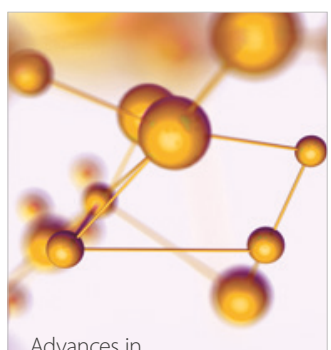

Physical Chemistry
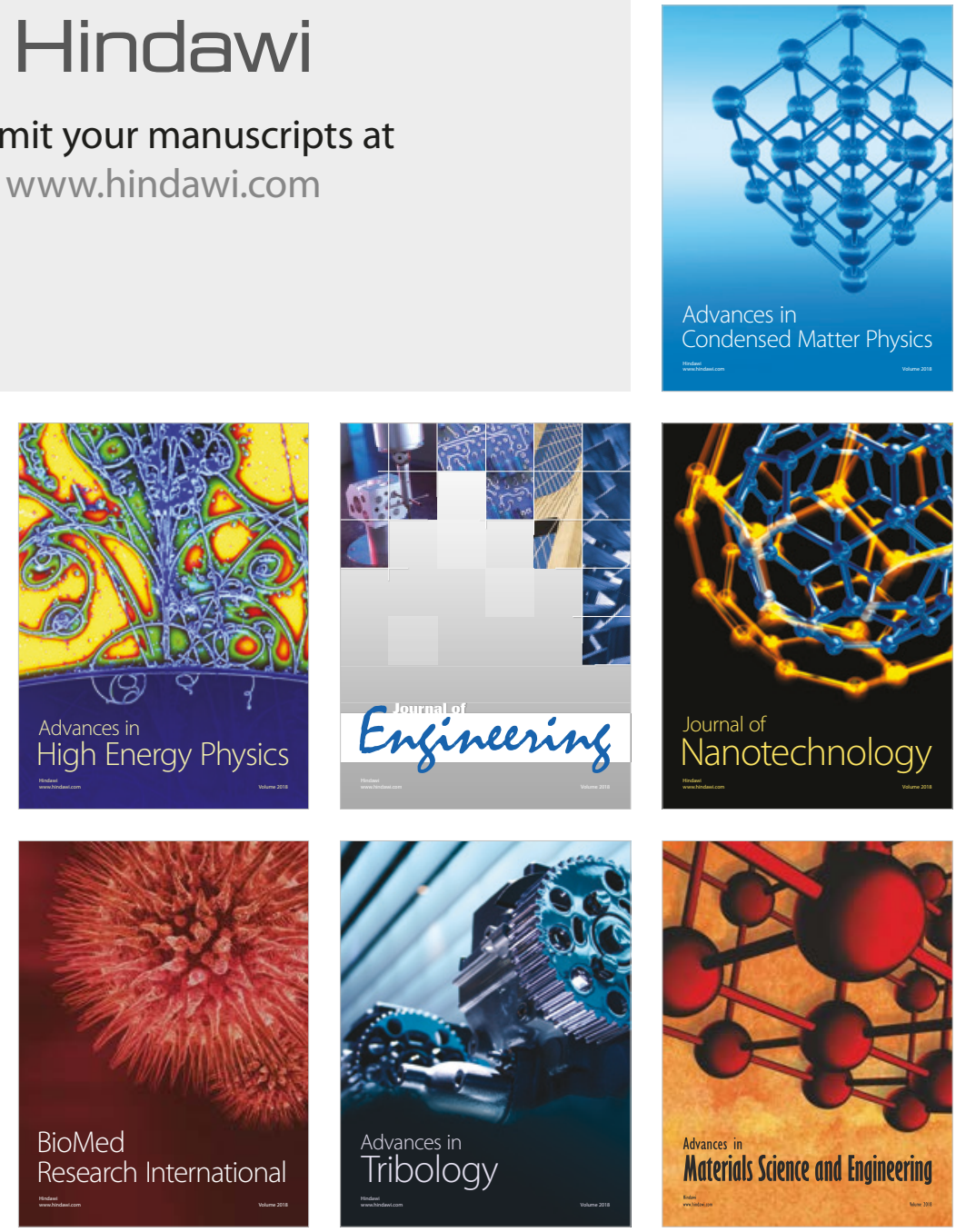